\title{
Change management and adoption of health information technology (HIT)/eHealth in public hospitals in Ghana: A qualitative study
}

Adoption of public hospitals in Ghana

\author{
Salifu Yusif, Abdul Hafeez-Baig and Jeffrey Soar \\ School of Management and Enterprise, University of Southern Queensland, \\ Toowoomba, Australia
}

\begin{abstract}
In Ghana, as with other developing countries, there are several health information technology (HIT) initiatives as interventions to improve healthcare delivery. HIT implementation undoubtedly results in change. However, most studies relating to HIT implementation readiness have constantly neglected the role of change in successfully implementing HIT. This study intends to identify factors affecting successful change management as part of preparation towards successfully implementing HIT in public hospital in Ghana. To carry out this study, we conducted in-depth interviews with a matrix of HIT senior managers and thematically analyzed the data. The data was transcribed and uploaded into a Nvivo 11 software for analysis using thematic analysis techniques. Five (5) themes were discovered. They are: 1) Stakeholder participation; 2) Proof of experience in similar project; 3) Availability of committed change agents/all-levels-change representatives; 4) Clearly articulated change implementation strategy; and 5) Training and improvement mechanism (postimplementation). A fresh call is made for more attention to be paid to change as part of preparatory measures towards the adoption of HIT in Ghana using the five cardinal approaches identified as a guide.
\end{abstract}

Keywords Change, HIT implementation, Healthcare organizations, Ghana, Developing countries

Paper type Original Article

\section{Introduction}

The struggle with inhumane circumstances such as lack of basic healthcare is more evident in Africa [1] due to severe shortage of healthcare provision on the continent. Africa is home to $14 \%$ of the World's population. However, it continues to struggle with $24 \%$ of the global

(C) Salifu Yusif, Abdul Hafeez-Baig and Jeffrey Soar. Published in Applied Computing and Informatics. Published by Emerald Publishing Limited. This article is published under the Creative Commons Attribution (CCBY 4.0) license. Anyone may reproduce, distribute, translate and create derivative works of this article (for both commercial and non-commercial purposes), subject to full attribution to the original publication and authors. The full terms of this license may be seen at http://creativecommons. org/licences/by/4.0/legalcode

The authors wish to acknowledge the support of the Australian Government Research Training Program (AGRTP).

Conflict of interest: The authors have no conflicts of interest to declare

Publishers note: The publisher wishes to inform readers that the article "Change management and adoption of health information technology (HIT)/eHealth in public hospitals in Ghana: A qualitative study" was originally published by the previous publisher of Applied Computing and Informatics and the pagination of this article has been subsequently changed. There has been no change to the content of the article. This change was necessary for the journal to transition from the previous publisher to the new one. The publisher sincerely apologises for any inconvenience caused. To access and cite this article, please use Yusif, S., Hafeez-Baig, A., Soar, J. (2019), "Change management and adoption of health information technology (HIT)/eHealth in public hospitals in Ghana: A qualitative study" Applied Computing and Informatics. Vol. 18 No. 3/4, pp. 279-289. https://10.1016/j.aci.2019.11.007. The original publication date for this paper was 30.11.2019.

Received 21 August 2019 Revised 23 November 2019 Accepted 26 November 2019 
burden of disease (GBD), and yet is served by just $3 \%$ of the world's health workers with access to merely $1 \%$ of world health expenditure [2]. Therefore, adopting platforms, which enable access to a pool of healthcare professionals globally to give a helping hand whenever possible in the unified goal of providing unlimited access to affordable and quality healthcare would have been seen to be the most important use of information and communication technologies (ICTs), specifically, health information technologies (HITs). Hence the tendency for e-Health projects to grow in number on the continent over time, in particular, countries with larger gross national incomes (GNIs) [3] to help improve health care delivery [4]. Many of them focus on telemedicine, health education and health-related research with a wide range of funding bodies, some of which have a geographical focus [3].

Although healthcare organizations are characterized by change, however, HIT related projects are a means of large-scale organizational change and transformation [5]. How HIT systems are 'implemented' in healthcare organizations remains a problem due to privacy, unauthorised access of information, data inaccuracies and interoperability. These problems constitute social and organizational challenges [6,7]. This is generally as a result of lack of availability of HIT systems especially in developing countries [8]. Several research efforts have focused on discovering the reasons behind the general lack of interest or resistance by key stakeholders. Implementing and leveraging on IT in healthcare organizations require stakeholders to change their behaviour, a concept that has received little attention. Thus, there need various stakeholder groups identified, considered, and involved during the implementation process [9]. Put more simply, e-Health initiatives must provide each stakeholder with at least one positive answer to the key change management question: "Why should I adopt or participate; what's in it for me?' Perhaps the most difficult question to answer, however, is "when will [e-Health] become part of the standard of care" [10]?

The adoption of information technology disrupts people and processes and causes change in organizations. Healthcare organizations are not immune to these changes. For instance, most electronic healthcare records (EHRs) are not designed to integrate, personalize and do not support longitudinal care of chronic illnesses or clinical operations in general as opposed to their ability to optimise the current encounter and improve billing efficiency [11]. The data in EHR are discrete and insufficient to support coordinated or continued care of patients living with chronic disease and or other forms of disability due to the independence of most clinical units [12]. The discrete nature of data stored in EHR may not be the only problem with coordinated patient care. Individuals from these independent units may resist change from any system that integrate them with other units as a result of past personal investments, uncertainty, lost in autonomy, identification with previous work or organizational routines and socio-political oppositions [13,14]. The unsettling effects from the adoption of information technology systems in organizations [15] take place almost always in a complex business and/or social environment [16]. Like many non-healthcare organizations, healthcare organizations will not reap the full benefits of a transition to using HIT unless they are able to successfully manage change in five areas, namely: leadership, talent management, technology, decision-making, and company culture [17]. These require a deeper understanding of current service/clinical processes that accomplish a particular purpose vis-à-vis willingness to mapping these processes and changing them to adapt to newly introduced HIT $[11,12]$

Health Information Management Systems Society (HIMSS) has defined change management for healthcare as "...process, approach and set of tools for managing the people side of change so that business results are achieved, on time, and within budget combines project management and human behavior" [18]. Many change programs need commitment from management, change implementers and change leadership in order to achieve long-term success [19]. Management leaderships in healthcare organizations while aiming at automating part or all of the workflow in the clinical settings need to recognize the 
internal and external factors that has the potential to affect the success of the intervention (commercial awareness) [20]. For example, introducing electronic healthcare systems. There are lists of focus, activities, and competencies of an effective transformational change methodology (See Anderson and Anderson [21].

Global health sector reform promises a period of new thinking and innovation in health systems that would address gaps in healthcare delivery including poor quality care, lack of accessibility among many others. The new thinking and innovation would require change among all ranks within healthcare organizations. They would include among other things the introduction of large-scale HITs, which in the past couple of years have struggled to be institutionalized as a result of inattentiveness to change as antecedent [22-25].

Against this backdrop, the aim of this paper is to identify factors to consider when introducing HIT as change in public hospitals in Ghana. We focused on public hospitals, specifically, tertiary institutions because in Ghana, like in other developing countries, there is a lot of pressure on public healthcare services to improve quality, access whilst being efficient. Hence the research question: What are the factors relevant to successful implementation of HIT as change in public hospitals in Ghana?

\section{Methods}

\subsection{Study design}

We conducted a qualitative research using in-depth interviews.

\subsection{Selection and recruitment of research population/sample}

eHealth adoption remains limited in Ghana and in other developing countries. As such, only participants with e-Health/HIT related experience were interviewed in this study (see Appendix 1) These participants included a matrix of lecturers, hospital administrator, heads of IT/CIOs in public healthcare institutions in Ghana. This population is believed to have the required knowledge needed to participate in this research study is involved in various e-Health initiatives in Ghana including a preliminary implementation of EHR systems in the above-mentioned participating hospitals. In addition to their knowledge about e-Health, previous small-scale e-Health research studies including Achampong [26], Adjorlolo and Ellingsen [27], Afagbedzi, Obuobi [28], Afarikumah [29], Sarfo and Asiedu [30] have used a similar sample. As a result, 13 of the 18 qualified invited participants participated. Five early participants were identified through identified eHealth initiatives in Ghana. The remaining participants were recruited based on referrals by early participants.

\subsection{Data collection procedures}

Between February and March 2018, in-depth one-on-one interviews lasting between 55 min and one hour, twenty minutes were conducted among 13 agreed participants. The interviews were audio-recorded using an iPhone 6 and later transcribed on a laptop. Interview guide, derived and formulated from existing relevant literature, see for example [9,13,19,22,31-36] were submitted to experts - academicians and HIT project leaders for validation - (context and relevance) ahead of scheduled interviews

Prior to collecting data, the study was submitted to relevant institutional ethics committees - the University of Southern Queensland (USQ) Human and Ethics application committee (H13REA149), the Committee on Human Research, Publication and Ethics Komfo Anokye Teaching Hospital in Ghana (CHRPE/AP/119) and permissions where relevant. An initial search on the Internet for HIT/e-Health initiatives revealed which organizations in Ghana were in one way or the other had e-Health related projects from which participants were selected. We used referrals where interviewees referred the interviewer to 
other potential participants. Change management readiness was identified in literature as relevant to e-Health readiness [9,31-33] but was not assessed as part of e-Health adoption readiness in previous studies. Interviewees were selected if they were/are involved in any HIT related project for a minimum of four years.

\subsection{Data analysis}

To analyse the data collected, we adapted the systematic guide to qualitative data analysis developed by Braun and Clarke [37] and O'Connor and Gibson [38] using Nvivo version 11 Software. In adapting to O'Connor and Gibson's guide, the researchers developed categories out of the identified ideas and concepts at the beginning of the data analysis process to enter the abstraction process. The transcribed data from various interviews in word document format were imported into the Nvivo 11 Software for thematic analyses by organizing data into nodes through coding. During the analysis of the imported data, text searches through Queries and word counts through word frequency queries were conducted. Thematic analysis is a form of pattern recognition within the data, where emerging themes become the categories for analysis. Initially the data were read and reread by all three authors to identify and index themes and categories: these mostly centered on phrases, incidents, or types of behavior. This phase, which re-focuses the analysis at the broader level of themes, rather than codes, involved sorting the different codes into potential themes, and collating all the relevant coded data extracts within the identified themes. In order to search for themes in the data being analyzed, the principal researcher essentially started by analyzing the codes and paid attention to how different codes may combine to form an overarching theme. Co-authors, $\mathrm{AH}$ $\mathrm{B}$ and JS being already familiar with the data, added comments and approved the results.

\section{Results and analysis \\ 3.1 Research sample}

13 qualified participants who had a minimum of four years working experience in healthcare environment and eHealth related projects were fully interviewed. The minimum education of these participants was undergraduate degree. Three were pursuing their master's degree, five had master's degree. One working in public health sector was pursuing a $\mathrm{PhD}$ degree. Another one held $\mathrm{PhD}$ and was a lecturer in the domain of information systems/technology (IS/T). The rest (three) held a bachelor bachelor's degree and had been managing various HIT related projects for at least four years and a maximum of ten years. All these participants had experience in eHealth, telehealth or telemedicine experience (ref to Appendix 1 for summary).

\subsection{Data analysis}

Five (5) themes emerged as important components of change as preparatory measures for the implementation of HIT in Ghana. They were 1. Stakeholder participation; 2. Proof of experience in similar project; 3 All-levels-change representatives; 4. Clearly articulated change implementation strategy; and 5. Training and improvement mechanism (postimplementation). Refer to Table 1 below for supporting statements.

\subsection{Exposition of themes}

The following is the explanation of assertions relating to themes above in Table 1.

\subsection{Stakeholder participation}

Most respondents in various assertions emphasized that end users (clinicians and administrators) need to participate in assessing the quality of the technology to be deployed. In the data gathered, it was revealed that HIT being adopted must be affordable, of good quality, accessible, and safe to use. A few previous related initiatives were not accepted 
Theme

No. of

Stakeholder participation

Proof of experience in related initiatives

Availability of change agents/all-level-levels-change representatives

Clearly articulated change implementation strategy

Training and improvement plan (Post-implementation)
Participants' comments

it does not mean that the doctors must come with us when we participants are sourcing the systems, what we actually want from them is their ability to tell us what kind of services they want the HIT to help with ... and a lot of them could easily see practically when using the systems their contribution” R4.

"Those at the helm of management surely need proof of every claim made" R7.

"Some time ago, we had to organize workshop and get people to tell us what we can do improve better system usage and what work for them" R6

"... .even sending them emails, using notice boards feedback/ comments box where people can tell you what they think or want is very helpful. . .no complains later. R11

"We are positive about these projects because we are able to provide them with proofs of well implemented past related initiatives. .." R2.

We have partnered with international organizations such as Novartis Foundation and successfully implemented telemedicine projects here. . to me there is more to it than just the success, but the guaranteed lessons learned worth more" R4.

"Most of us have implemented IT projects in different industries before coming here. So, I haven't seen any much challenge here. "What is important is that we get the right people to tell their stories of what they want. . let me just say gathering system requirements" R9

"In every facility where we are proposing to pilot these systems, we already have some individuals doing the talking for us..." R5

"You notice that when the doctors recommend the systems, the nurses are in for because generally they follow the orders of the doctors" R13.

"We try to make sure we are everywhere in order to get our messages across so everyone is aware of what is coming. . .you know, it's not other things where you can surprise people and they are happy. For IT stuff, people become even more frustrated when they see things and can't figure out how they work" R3

"we did this by dispatching our teams to go around interacting with end-users about potential concerns regarding interruptions even though there were not many interruptions that had any prohibitive consequences" R1.

"We inform them of any plans we have especially when it is a massive system work. . .system-wide upgrade and others R11 "Trust me; people always have problems that they want solved and there has to be reliable way to do that" R7.

"One thing that we noticed was that our stakeholders want be make sure that we are always available to help them with the usage of the systems. I mean they get stuck or the systems aren't working" R12.

“. . . continue updating and supporting them so they can maximize system usage. . . it also help with less system problems because they are able to use the system well with no much mudding” R8
Adoption of public hospitals in Ghana

283

Table 1.

Key themes and corresponding respondent comments. 
$\mathrm{ACI}$ $18,3 / 4$

by end-users even though they could see benefits in using such systems but generally because they were not involved, they had a feeling of not owing such systems and that their thoughts were not regarded as relevant.

Respondents did agree on the fact that even though physicians were aware of the potentials of HIT to improve the quality of healthcare delivery, they still wanted to fully be consulted and be involved in all the processes leading up to HIT implementation. Majority of the respondents were of the view that for management leadership, more still need to be done in talking them into understanding and recognizing that HIT is a tool when properly implemented can help improve healthcare delivery and improve revenue in the end. For healthcare providers, however, to switching from manual to computers or electronic when recording patients' information, they do think the pressure in the context of poor doctor/patient ratios; systems reliability and sustainability were issues of concern - slow typing and other system use issues.

\subsection{Proof of experience in related initiatives}

Even though past successes do not guarantee future successes, they do, however, provide some form of platform to begin the journey of organizational change matters in the healthcare environment. Data analyzed showed that past experience could buttress proposals for future HIT projects.

\subsection{Availability of committed change agents/All-levels-change representatives}

When exploring the effect of multicultural nature of the Ghanaian society and change, participants contend that blanket decisions must not be made when it comes to effecting change. Change processes must be considered in various layers. In the data, it was apparent that stakeholder groups and level representatives was considered relevant for the successful implementation of HIT. For instance, for healthcare providers, there must be some representatives who understand the nature of the roles of healthcare providers. At the community level, there must be community change teams and so on.

It was apparent in the data that for any HIT to be successful, change workshops aimed at addressing fears and resistance were inevitable. These workshops must be ongoing to making sure that continuous difficulties that may cause users of implemented systems to give must were all addressed.

\subsection{Clearly articulated change implementation strategy}

According to respondents, it was very crucial to ensure that materials or resources that stipulate systems' implementation plans- phases/dates, potential disruption, etc were available. This change strategy for instance was found be effective. According respondents, they made sure end-users were involved in devising implementation strategies as a way of minimizing surprise disruptions and chaos knowing that normal working days are already under pressure.

From the data, it is understood that with clear advance information available to immediate stakeholders such as doctors and other administrative staff, there will be more support base and less resistance.

\subsection{Training and improvement plan (Post-implementation)}

In data, there were elements suggesting that to successfully deal with change issues, there was the need for a two-way communication.

Communication plays a key role in change. On this, participants expressed opinions concerning the fact that establishing channels for people impacted by any change brought about the implementation of any system was crucial. In order words, feedback mechanism is an interactive platform where stakeholders can be supported. 


\section{Discussion}

Change is inevitable in the subsistence and success of the present ever cost increment industry of healthcare. The findings from this study provide an understanding of five key approaches to consider when dealing with change principally among healthcare providers when it comes to the introduction of HITs. These themes appear to be cardinal whenever the thoughts of HIT readiness and adoption comes to decision-making tables and a point of departure from the notion of resistance and low HIT acceptance among healthcare providers. According to this study, the participation of end users was found to be crucial for the successful implementation of HIT in healthcare facilities in Ghana. End users such as doctors are in a better position to explain clinically aspects of their work they wish to be helped with. When users are involved in the process of HIT initiative, issues of change become easier as most of them might have already been aware of what to expect. Thus, user and other stakeholder participation is important in identifying problem and in understanding user requirements prior to designing systems as solutions [15]. This is congruent with the findings of Ahmad and colleagues. According to Ahmad, Kyratsis [39], key stakeholder involvement can lead to innovation adoption and implementation of systems compatible with structural and cultural contexts, particularly when involvement crosses the phases of initiation, decision-making and implementation. When stakeholders such as healthcare providers participate in decisions leading up to the implementation of HIT, they were more likely to accept and make meaningful use of HIT perceiving it as theirs.

As accessibility, affordability and quality chaos continues to overwhelm healthcare organizations, the focus of HIT continues to center on how to improve adoption and implementation outcomes. "Knowledge-based view focuses on strategy development and its implementation based on appropriate and comprehensive know-how about the phenomenon under consideration [HIT] [40]. The reality is that change management, when properly implemented and aligned with technology, leads to reduced failures, reduced wate of resources and alignment with higher levels of IT [41]. On occasions such as determining the readiness of healthcare institutions to adopting HIT, knowledge-based views emanating from past experiences and lessons learned will prove to be crucial given a high rate of failures in HIT projects. It worth noting that most of the failures has to do with acceptance and improper implementations. For many of the respondents, one important means of successfully changing mindsets and gaining support was show evidence of past successes, which most respondents were confident to refer to as part of records of accomplishments. It is important to mention, though, that most of these successful projects were sponsored and led by donor organizations who had control over how the projects were being managed. With the debate over past success and lessons learned, one common element stood out clear in the data and in this study, the need to always treat each project different. A large portion of the participants think that the IT industry is a fast changing one compared with other industries. This makes the successful management of IT project in developing countries a bit more difficult as they mostly lag their developed counterparts. If past performance can serve as a predictor of future performance in pre-clinical training [42], then certainly, it can also predict whether HIT system to be deployed will be successful or not.

According to this study, evidence from data suggests that all stakeholders particularly management leadership bet on past performance. This was perhaps because past performance affects the beliefs in one's personal capability and serves as the cause of future actions [43]. The saying "best predictor of future behavior is past behavior" [44] is one that stakeholders stand by as a premise in making most decisions. It was apparent from the study that stakeholders, particularly sponsors believe the way to predict the ability of proponents of HIT to successfully implement a reliable HIT was to look at what they have achieved in the past. This approach to change appeared in the data as a great platform for change agents/leaders to send clear message of reliable anticipated changes to their sceptics and are always confident in interacting with them through feedback mechanism.
Adoption of public hospitals in Ghana 
How to assure stakeholders of the stability, reliability and sustainability of the HIT systems to be deployed amid lack of proper and reliable technology infrastructure in the context of developing countries remains a quagmire. "Good management of change is a sine qua non" [45]. For change to be well managed, there also requires change leaderships to bring into line their advocacy and enacted values [46]. This will enhance the readiness to embrace organizational change as result of increased motivation and performance on the change in work flow/process [35] as they seek more challenges in order to perform their duties.

While management leadership, board of directors, and external government agencies such the Ministry of Health and Ghana Health Services according to data analyzed appear to be concerned with cost reduction and efficiency when delivering care services, it was obvious there were also concerns about healthcare organizational culture relating to in-person presentation by patients and other workflow issues. Healthcare providers appeared to be more concerned about system functionality and reliability in the context of their work and how to reach out to more patients [47]. Perhaps, presented differently, the goal has never changed. Thus, increase accessibility and quality while reducing cost remain the convincing theme advocates of HIT have based their cases on.

People and processes get affected by the introduction of new systems. These effects require effective and comprehensive change process and management to minimize any foreseeable impact. The context of the data suggests that most HITs are not new to physicians, however, there exist few concerns on the ground. It appears that good and reliable ICT infrastructure will play a key role in the change the mindset of users. From data, there are elements of physicians' concerns regarding moments when systems may not be available (downtimes) resulting in poor healthcare delivery.

However, there still exist gaps in what constitutes a comprehensive change process through changes to the subsystems of organization [48]. Given the diverse stakeholders of healthcare organizations and their multi locations, the implementation of HIT and change initiatives is across departments, locations or teams as well as at the individual levels [49], there need to be a multilevel/location change agents for effective change process. On effective change process, opined that arguably, the most popular approach is the wide-spread participation of relevant stakeholders as an antidote to resistance whilst creating psychological ownership [48]. These change agents could be healthcare providers, community advocates and other proponents of HIT in healthcare organizations. In effect, a multi-layer change teams, according to the data were relevant because there exist stakeholder dynamics. They are complex - being the result of the collaboration of many factors including culture, structure and personalities.

Like ERP implementation, healthcare organizations' approaches for promoting HIT implementation success according to data analyzed included but were not limited to change strategy development and deployment, change management techniques and project management [50]. The strategies also outlined details of HIT implementation to minimize any disruption while increasing awareness and confidence among implementation teams and end users as well as training and system maintenance and improvement (post-implementation) strategies. Both practitioners and scientists agree that organizational change communication is the most effective strategy to improve employee adjustment to change [35]. An important part of change, as found in the data was ongoing support and that people at risk of being impacted must be assured that they would not be alone. Increasingly, as a starting point, there "report an issue" e-mails being created as part of feedback mechanisms and emergency lines for technicians to be contacted whenever there are issues that need immediate response.

\section{Conclusion}

HIT has come to stay and is making its way gradually into aspects of mainstream healthcare delivery in Ghana as well as in other developing countries amid many challenges. In this 
study, change, which was identified as a very influential predictor of HIT implementation outcome, has, however, lacked attention in previous related studies. We therefore make fresh call for the need for more attention to be paid to change in the context of the five identified components when embarking on HIT implementation initiatives for successful healthcare organization change. The study also found that there are multiple stakeholders with differing interest necessitating the need for multi-layered change teams to arrest the concerns of sceptics and institute hope in them by dwelling on past successes with HIT related initiatives. As the implementation of HIT results in changes, the study further found that advance clear and reliable anticipated change information contribute towards successful change management and effective HIT implementation.

\section{References}

[1] R. Scott, M. Mars, Telehealth in the developing world: current status and future prospects, OncoTargets Therapy 8 (2015) 289-294.

[2] World Health Organization World Health Report 2006: Working Together for Health. 2006ß, World Health Organization: Geneva: WHO Press. p. 1-209.

[3] M. Jahangirian, S. Taylor, Profiling e-health projects in Africa: trends and funding patterns, Information Dev. (2013), p. 0266666913511478.

[4] Ackerman, K. Developing Countries See Promise in E-Health; Challenges Remain. 2010 [cited 201228 December 2012]; Available from: http://www.healthbeat.org/.

[5] M. Martinsuo, P. Hoverfält, Change program management: Toward a capability for managing value-oriented, integrated multi-project change in its context, Int. J. Project Manage. 36 (1) (2018) $134-146$.

[6] F. Ozair et al., Ethical issues in electronic health records: A general overview, Perspec. Clin. Res. 6 (2) (2015) 73.

[7] R. Kohli, S. Tan, Electronic health records: how can IS researchers contribute to transforming healthcare?, Mis Quarterly 40 (3) (2016) 553-573.

[8] A. Ahlan, B. Ahmad, User acceptance of health information technology (HIT) in developing countries: A conceptual model, Proc. Technol. 16 (2014) 1287-1296.

[9] A. Lackner, Implementation guide for patient generated health information in healthcare organizations. 2015.

[10] P.J. Heinzelmann, N.E. Lugn, J.C. Kvedar, Telemedicine in the future, J. Telemed. Telecare 11 (8) (2005) 384-390.

[11] C. Jaén, Successful health information technology implementation requires practice and health care system transformation, Ann. Family Med. (2011).

[12] J. Walker, P. Carayon, From tasks to processes: the case for changing health information technology to improve health care, Health Aff. 28 (2) (2009) 467-477.

[13] G. O'Brien, Participation as the key to successful change-a public sector case study, Leadership Org. Dev. J. 23 (8) (2002) 442-455.

[14] A. Thornhill et al., Managing Change. A Human Resource Strategy Approach. Harlow, Financial Times Prentice Hall, 2000.

[15] Y. Dwivedi et al., Research on information systems failures and successes: Status update and future directions, Inform. Syst. Front. 17 (1) (2015) 143-157.

[16] D. Bunker, L. Levine, C. Woody, Repertoires of collaboration for disaster management: Negotiating emergent and dynamic systems success, International Working Conference on Transfer and Diffusion of IT, Springer, 2013.

[17] A. McAfee et al., Big data: the management revolution, Harvard Business Rev. 90 (10) (2012) $60-68$.
Adoption of public hospitals in Ghana 
$\mathrm{ACI}$

$18,3 / 4$

288
[18] Hartmann, C. Management Engineering \& Process Improvement Community 2014 [cited 2017 27/ 05]; Available from: www.himss.org/file/1256356/download.

[19] L. Narine, D. Persaud, Gaining and maintaining commitment to large-scale change in healthcare organizations, Health Services Manage. Res. 16 (3) (2003) 179-187.

[20] Hayes, J., of The theory and practice change management. 2018.

[21] D. Anderson, L. Anderson, Beyond Change Management: How to Achieve Breakthrough Results Through Conscious Change Leadership, John Wiley \& Sons, 2010.

[22] L. Anthopoulos et al., Why e-government projects fail? An analysis of the Healthcare. gov website, Govern. Inform. Q. 33 (1) (2016) 161-173.

[23] J. Braa et al., Developing health information systems in developing countries: the flexible standards strategy, Mis. Q. (2007) 381-402.

[24] R. Taylor et al., Promoting health information technology: is there a case for more-aggressive government action?, Health Aff. 24 (5) (2005) 1234-1245.

[25] C. Avgerou, The significance of context in information systems and organizational change, Inform. Syst. J. 11 (1) (2001) 43-63.

[26] E. Achampong Electronic Health Record System: A Survey in Ghanaian Hospitals. 1: 164. doi: 10. 4172/scientificreports. 164 Page 2 of 4.1 (2), 2012 Hospital in 1921, and it was finally opened on 9th October, 1923. The hospital has expanded in phases and now has, 2012. 1600.

[27] S. Adjorlolo, G. Ellingsen, Readiness assessment for implementation of electronic patient record in Ghana: a case of University of Ghana Hospital, J. Health Inform. Dev. Countries 7 (2) (2013) $128-140$.

[28] S. Afagbedzi et al., A Review of Ghana's E-health strategy, J. Health Inform. Africa 1 (1) (2013).

[29] E. Afarikumah, Electronic health in Ghana: Current status an future prospects, Online J. Public Health Inform. 5 (3) (2014) 230.

[30] J. Sarfo, M. Asiedu, Ehealth efficacy in Ghanaian nursing: a pilot thematic analysis on benefits and challenges, Eur. Sci. J. 9 (23) (2013).

[31] R. Heeks, Health information systems: Failure, success and improvisation, Int. J. Med. Inf. 75 (2) (2005) 125-137.

[32] E. Ford, N. Menachemi, M. Phillips, Predicting the adoption of electronic health records by physicians: when will health care be paperless?, J. Am. Med. Inform. Assoc. 13 (1) (2006) 106-112.

[33] Huang, W., J. Seitz and N. Wickramsinghe, Manifesto For E-health Success, 2010.

[34] Hartmann, C. Management Engineering \& Process Improvement Community 2014 [cited 2017 05/ 27/2017]; Available from: www.himss.org/file/1256356/download.

[35] P. Petrou, E. Demerouti, W. Schaufeli, Crafting the change: The role of employee job crafting behaviors for successful organizational change, J. Manage. 44 (5) (2018) 1766-1792.

[36] S. Adjorlolo, G. Ellingsen, Readiness assessment for implementation of electronic patient record in Ghana: a case of university of Ghana hospital, J. Health Inform. Dev. Countries 7 (2) (2013).

[37] V. Braun, V. Clarke, Using thematic analysis in psychology, Qualitative Res. Psychol. 3 (2) (2006) 77-101.

[38] H. O'Connor, N. Gibson, A step-by-step guide to qualitative data analysis, Pimatisiwin: J. Indigenous Aboriginal Commun. Health 1 (1) (2003) 63-90.

[39] R. Ahmad, Y. Kyratsis, A. Holmes, When the user is not the chooser: learning from stakeholder involvement in technology adoption decisions in infection control, J. Hosp. Infect. 81 (3) (2012) 163-168.

[40] S. Gupta et al., Organizational, technological and extrinsic factors in the implementation of cloud ERP in SMEs, J. Org. Change Manage. 31 (1) (2018) 83-102.

[41] Arredondo, R., Change Management Approach to Achieve Healthcare IT Adoption in SierraCedar. 2015. 
[42] K. Stegers-Jager et al., Predicting performance: Relative importance of students' background and past performance, Med. Educ. 49 (9) (2015) 933-945.

[43] M. Salanova, I. Martínez, S. Llorens, Success breeds success, especially when self-efficacy is related with an internal attribution of causality, Estudios de Psicología 33 (2) (2012) 151-165.

[44] Levin, J. and J. Wyckoff, Student Characteristics That Predict Persistence and Success in Baccalaureate Engineering. 1990, p.11.

[45] R. Gill, Change management-or change leadership?, J. Change Manage. 3 (4) (2002) 307-318.

[46] A.-L. Holten, S. Brenner, Leadership style and the process of organizational change, Leadership

Adoption of public hospitals in Ghana Org. Dev. J. 36 (1) (2015) 2-16.

[47] M. Rawashdeh et al., Reliable service delivery in Tele-health care systems, J. Network Computer Appl. 115 (2018) 86-93.

[48] S. Fernandez, H. Rainey, Managing successful organizational change in the public sector, in: Debating Public Administration, Routledge, 2017, pp. 7-26.

[49] K. Whelan-Berry, J. Gordon, C. Hinings, Strengthening organizational change processes: Recommendations and implications from a multilevel analysis, J. Appl. Behav. Sci. 39 (2) (2003) 186-207.

[50] A. Aladwani, Change management strategies for successful ERP implementation, Business Process Manage. J. 7 (3) (2001) 266-275.

\section{Appendix}

\section{Appendix 1}

Sample for qualitative data collection.

\begin{tabular}{llcr}
\hline Distribution of sample & No. Invited & No. Participated & \\
\hline 1 & Project leaders/Managers & 2 & 2 \\
2 & Head of IT & 1 & 1 \\
3 & Head of IT, Head of applications and Director General & 3 & 1 \\
4 & Coordinator & 1 & 1 \\
5 & HIT coordinator & 1 & 2 \\
6 & Head of IT, Administrative Manager & 3 & 1 \\
7 & lecturers & 1 & 1 \\
8 & Director of information management & 1 & \\
9 & Head of IT, Senior Admin officer & 2 & 2 \\
10 & 2 & 18 & 13 \\
Total & Head of IT, Senior Admin officer & & \\
& &
\end{tabular}

\section{Corresponding author}

Salifu Yusif can be contacted at: salifusf5@gmail.com

For instructions on how to order reprints of this article, please visit our website:

www.emeraldgrouppublishing.com/licensing/reprints.htm

Or contact us for further details: permissions@emeraldinsight.com 